\title{
DISTRIBUTION, BEHAVIOR, AND CONSERVATION STATUS OF THE RUFOUS TWISTWING (CNIPODECTES SUPERRUFUS)
}

\author{
JOSEPH A. TOBIAS,,$^{1,7}$ DANIEL J. LEBBIN, ${ }^{2}$ ALEXANDRE ALEIXO, ${ }^{3}$ \\ MICHAEL J. ANDERSEN, ${ }^{4}$ EDSON GUILHERME, ${ }^{5}$ PETER A. HOSNER,${ }^{6}$ AND \\ NATHALIE SEDDON ${ }^{1}$
}

\begin{abstract}
The Rufous Twistwing (Cnipodectes superrufus), a newly described Amazonian tyrant-flycatcher, is known from five specimens and five localities in Cuzco and western Madre de Dios departments, Peru. We report three additional specimens and eight new localities extending the known range of the species east across Dpto. Madre de Dios, Peru, into Dpto. Pando, Bolivia, and Acre State, Brazil. The new localities increase the distribution from $\sim 3,400$ to $\sim 89,000 \mathrm{~km}^{2}$. We collected biometric data from five individuals, made behavioral observations in the field, and recorded three separate types of vocalizations, two of which (including the song) were previously unknown. We provide quantitative description of these vocalizations, consider their function, and compare them with vocalizations of the only known congener, the Brownish Twistwing (Cnipodectes subbrunneus). Unique vocal repertoires support the classification of these two forms as sister species. The Rufous Twistwing resembles the Brownish Twistwing in producing loud vocalizations from regular song posts and both species appear to have a polygamous mating system. We provide further evidence consistent with the hypothesis the Rufous Twistwing is a Guadua bamboo specialist and recommend that it be listed as Vulnerable on the IUCN Red List. Received 5 July 2006. Accepted 23 March 2007.
\end{abstract}

The Rufous Twistwing (Cnipodectes superrufus) is a large, distinctive tyrant-flycatcher from southwest Amazonia. It occurs in a region relatively well studied by ornithologists, but was only recently described and little is known about its behavior, distribution, and population size (Lane et al. 2007).

The only previous publication considered the Rufous Twistwing likely to be a Guadua bamboo specialist, but noted that it was almost certainly heard in "river-edge thicket vegetation with no bamboo growth visible" at Manu Lodge $\left(12^{\circ} 06^{\prime} \mathrm{S}, 71^{\circ} 06^{\prime} \mathrm{W}\right.$; elevation $340 \mathrm{~m}$ ) in 1991 and 2000 (Lane et al. 2007: 768). The five confirmed localities (Lane et al.

\footnotetext{
${ }^{1}$ Edward Grey Institute, Department of Zoology, University of Oxford, South Parks Road, Oxford, OX1 3PS, United Kingdom.

${ }^{2}$ Department of Ecology and Evolutionary Biology, Cornell University, E148 Corson Hall, Ithaca, NY 14853, USA.

${ }^{3}$ Museu Paraense Emílio Goeldi, Coordenação de Zoologia, Caixa Postal 399, 66040-170, Belém PA, Brazil.

${ }^{4}$ Macaulay Library, 159 Sapsucker Woods Road, Ithaca, NY 14850, USA.

${ }^{5}$ Universidade Federal do Acre, Departmento de Ciências da Natureza, BR-364, km 04, Campus, 69915-900, Rio Branco AC, Brazil.

${ }^{6}$ Cornell Museum of Vertebrates, 159 Sapsucker Woods Road, Ithaca, NY 14850, USA.

${ }^{7}$ Corresponding author; e-mail: joseph.tobias@zoo.ox.ac.uk
}

2007) encompass a small area $\left(\sim 3,400 \mathrm{~km}^{2}\right)$ in western Dpto. Madre de Dios and Dpto. Cuzco, Peru. However, the existence of large blocks of Guadua bamboo-dominated terra firme forest in southwestern Amazonian Brazil, southeastern Peru, and northwestern Bolivia (Silman et al. 2003) suggest the global distribution of the species may be extensive (Lane et al. 2007).

The only published vocalization is an agitation call (Lane et al. 2007), whereas the full vocal repertoire is likely to be similar to that of the Brownish Twistwing (C. subbrunneus), a presumed sister species with at least three distinct vocalizations (Parker and Remsen 1987, Schulenberg et al. 2000, Ridgely and Greenfield 2001). Male Brownish Twistwings are notably disinterested in playbacks of their songs, which are given from small, stable, and often adjacent territories, suggesting a polygynous mating system (Parker and Remsen 1987, Ridgely and Tudor 1994, Ridgely and Greenfield 2001, Fitzpatrick 2004). Lane et al. (2007) reported no information regarding the breeding behavior of Rufous Twistwing.

In this paper we report: (1) new localities, (2) vocalizations, (3) habitat preferences, and (4) behavior of the Rufous Twistwing to add to the details presented by Lane et al. (2007). We also assess the conservation status of the species, based on our results, following IUCN Red List criteria (IUCN 2001). 


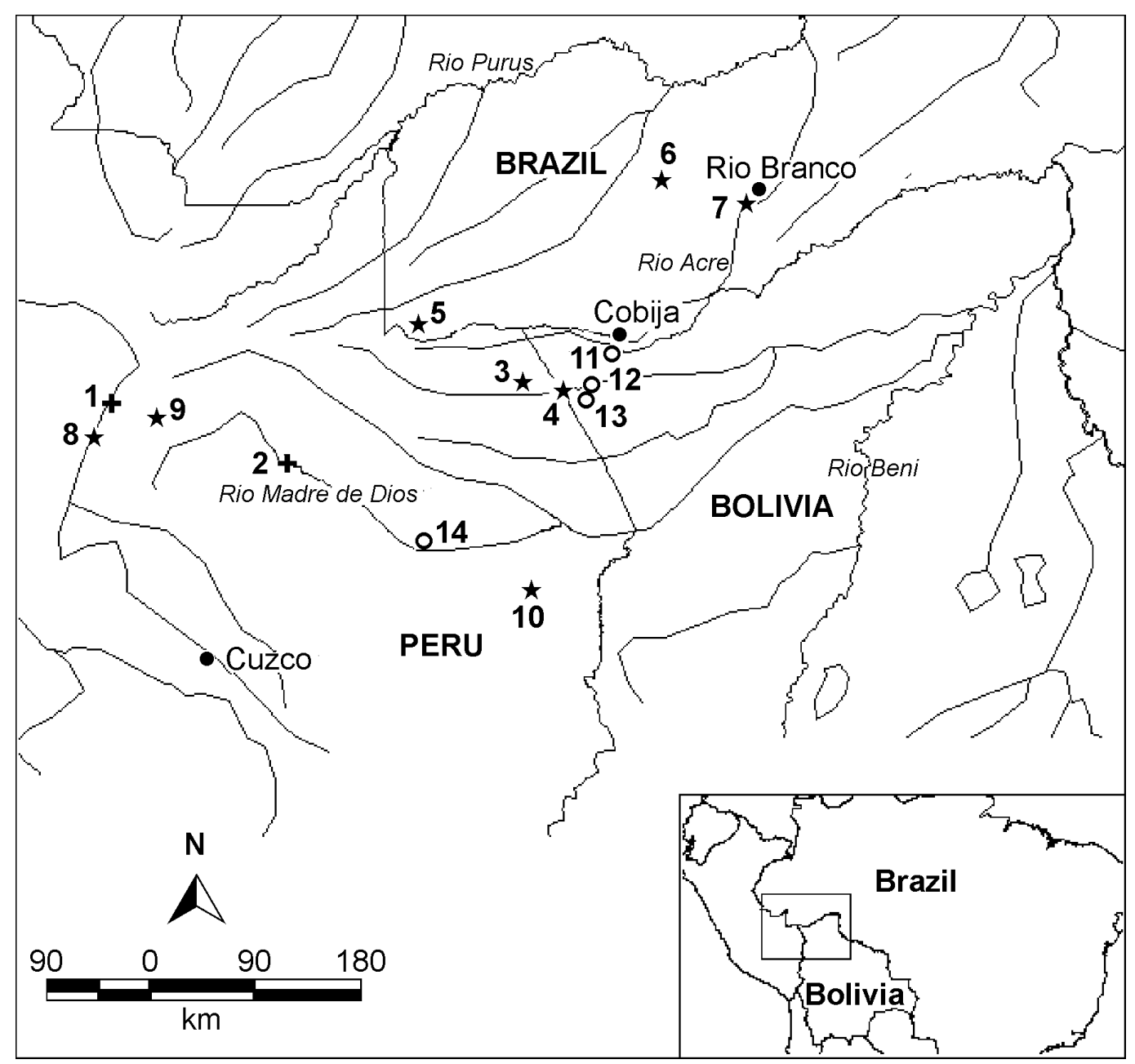

FIG. 1. Sites mentioned in the text mapped in relation to major cities (closed circles), rivers, and international boundaries. Crosses indicate the previously known range of Rufous Twistwing in Peru: (1) Río Urubamba centered on Camisea, and (2) Río Manu centered on Pakitza, Dpto. Madre de Dios (type locality). Stars indicate new localities for the species: (3) Oceanía, Dpto. Madre de Dios, Peru; (4) Extrema, Dpto. Pando, Bolivia; (5) Estação Ecológica do Rio Acre, Acre State, Brazil; (6) Ramal Jarinal, Acre State, Brazil; (7) Rio Branco, Acre State, Brazil; (8) Timpía, Dpto. Cuzco, Peru; (9) Montetoni, Dpto. Cuzco, Peru; and (10) Tambopata, Dpto. Madre de Dios, Peru. Open circles indicate study sites where C. superrufus was absent: (11) Camino Mucden, Dpto. Pando, Bolivia; (12) Palmera, Dpto. Pando, Bolivia; (13) San Sebastián, Dpto. Pando, Bolivia; and (14) CICRA, Dpto. Madre de Dios, Peru.

\section{METHODS}

Study Sites and Survey Methods.-We surveyed six Guadua-dominated forest sites in southwestern Amazonia, including one site in Bolivia and three in Brazil. Avifaunal surveys were undertaken by three independent teams at field sites using different methods at each site except CICRA and Oceanía where the same methods were used. Playback of pre-re- corded Rufous Twistwing calls was used opportunistically at sites $1-3$; in all cases we used the agitated calls recorded by Thomas Valqui H. at Kirigueti, Dpto. Cuzco, (i.e., Fig. $3 \mathrm{~A}$ in Lane et al. 2007). Additional records were sought from experienced observers. Localities were mapped (Fig. 1) and range sizes measured using equal-area projections with ArcView 3.2. 
1. Centro de Investigación y Capacitación Río Los Amigos (CICRA), 270 m, Dpto. Madre de Dios, Peru $\left(12^{\circ} 35^{\prime} \mathrm{S}, 6^{\circ} 12^{\prime} \mathrm{W}\right)$, 2001-2007. This research station is at the confluence of the Río Los Amigos and the Río Madre de Dios in the Los Amigos Conservation Concession, a 135,000-ha private concession managed by Amazon Conservation Association. DJL, MJA, PAH, JAT, and NS surveyed multiple patches of Guadua weberbaueri and $G$. sarcocarpa bamboo for multiple bird species over a 7-year period using random transects, field observations, tape-recording, and intensive mist netting. This site includes camp CM1 on the south bank of the Río Los Amigos.

2. Oceanía, $250 \mathrm{~m}$, Dpto. Madre de Dios, Peru $\left(11^{\circ} 23^{\prime} \mathrm{S}, 69^{\circ} 32^{\prime} \mathrm{W}\right), 11-18$ October 2004. This locality is $6 \mathrm{~km}$ west of Iberia, a town $\sim 130 \mathrm{~km}$ north of Puerto Maldonado on the Iñapari road. DJL, MJA, and PAH surveyed a large patch of Guadua weberbaueri and G. sarcocarpa bamboo, in places collapsing to form impenetrable thickets with a canopy at $\sim 4 \mathrm{~m}$. The bamboo patch was on an upland terrace, bordered by land recently cleared and burned for agriculture, extending to the nearby Río Tahuamanu (to the east and south), as well as successional forest and mature forest (to the north, south, and west). The presence of burned and chained logs, and a logging road revealed a recent history of human disturbance. We conducted daily censuses using random transects between 0445 and 1000 hrs EST (12-16 Oct), and operated mist nets daily from dawn until midday (11-17 Oct). A combination of 6- and 12-m nets were rotated over 30 net locations covering a total length of $700 \mathrm{~m}$ of trail in 7 days. Total effort was $\sim 400$ net hrs (for 12-m nets).

3. Extrema, $250 \mathrm{~m}$, Dpto. Pando, Bolivia $\left(11^{\circ} 28^{\prime} \mathrm{S}, 6^{\circ} 15^{\prime} \mathrm{W}\right), 6-9$ November 2004. This military outpost is $\sim 45 \mathrm{~km}$ east-southeast of the Oceanía site on the banks of the Río Tahuamanu where this river flows from Peru into Bolivia. The natural habitat appears to be forest with an open canopy and an understory largely composed of Guadua bamboo. JAT and NS surveyed habitat here and at the adjacent guard-post of Alto Peru, $1 \mathrm{~km}$ north in Dpto. Madre de Dios, Peru. We surveyed habitat with and without bamboo on random transects between 0445 and $1800 \mathrm{hrs}$ daily (6-9 Nov), spending 18 hrs in bamboo at Extrema and 2 hrs in bamboo at Alto Peru, Madre de Dios, Peru (2 km from Extrema).

4. Estação Ecológica do Rio Acre, 250$350 \mathrm{~m}$, Acre State, Brazil $\left(11^{\circ} 03^{\prime} \mathrm{S}, 70^{\circ} 12^{\prime}\right.$ W) on the border with Peru, 13-24 August 2005 and 3-15 February 2006. Site A was surveyed in 2005 by AA, including riparian forest along Rio Acre and a small tributary (Igarapé do Tombo); AA and EG surveyed site $\mathrm{B}, \sim 7 \mathrm{~km}$ west of site $\mathrm{A}$, in 2006 . Extensive patches of Guadua bamboo were present at both sites. Field effort included $\sim 250 \mathrm{hrs}$ of random transects through the main vegetation types, observing, mist netting, tape-recording, and collecting birds.

5. Rio Branco, $250 \mathrm{~m}$, Acre State, Brazil (095 57' S, 67 57' W), 1998-2006. Long-term fieldwork is being conducted by EG at Parque Zoobotânico, a field station managed by Universidade Federal do Acre. The site is within the suburban limits of Rio Branco and the habitat ( $\sim 100$ ha of humid forest with patches of Guadua sarcocarpa and G. weberbaueri bamboo) is becoming increasingly disturbed and isolated by peripheral clearance (Guilherme 2001). The main survey technique was mist netting: 10 mist nets $(12 \mathrm{~m})$ were operated for 6 hrs/day (usually dawn until midday) on $\sim 35$ days/year (evenly split between dry and wet seasons). Annual mist netting effort was $\sim 2,000$ net hrs.

6. Ramal Jarinal, $320 \mathrm{~m}, \sim 100 \mathrm{~km}$ WNW of Rio Branco, Acre State, Brazil (09 $54^{\prime} \mathrm{S}$, $\left.68^{\circ} 28.5^{\prime} \mathrm{W}\right), 12-22$ November 2006. EG and Marcos Pérsio D. Santos (Universidade Federal do Piauí) surveyed this site and collected specimens. The habitat was terra firme forest dominated by bamboo (Guadua sarcocarpa and G. weberbaueri) and palms (e.g., Attalea sp.) with high human disturbance including recently cleared cattle pastures and selective logging.

Sound Recording, Analysis, and Playback Experiments.-Recordings of vocalizations were made at Oceanía and Extrema using a Sennheiser ME 67 shotgun microphone with a Sony PCM-M1 MiniDAT or a Sony TC-D5 Pro II Cassette Recorder. All recordings are deposited at the Macaulay Library (ML) at Cornell University.

Recordings were automatically filtered and digitized at a sampling frequency of $44.1 \mathrm{kHz}$ 
using Avisoft SASLabPro Version 4.15 (C) 2002 Raimund Specht, Berlin, Germany) with a 16-bit acquisition sound card (0 VIA [Wave] 5.10). Sonograms were generated using standard broadband $(216 \mathrm{~Hz})$ filter settings (FFT $=1,024$, Frame $=75 \%$, Window $=$ FlatTop, Overlap $=87.5 \%$ ). Sonograms were inspected visually, assigned to three types, and described quantitatively using on-screen cursors to measure standard temporal (sec) and frequency $(\mathrm{kHz})$ parameters: overall duration, duration of first note, duration of middle note, duration of final note, number of notes, pace of notes (notes/min within a vocalization), pace of calls (calls/min within a recording), maximum overall frequency, minimum overall frequency, and bandwidth.

Playback experiments were conducted at Extrema to investigate the function of vocalizations. Recordings were played through a Sony SRS-58 speaker from a range of 10-40 $\mathrm{m}$; the subject of most playbacks (7/10) was the individual from which the tape was recorded. Samples were too small to permit statistical analysis.

\section{RESULTS}

Field Observations.-Intensive field work at CICRA has not yet produced records of the Rufous Twistwing, despite extensive bamboo and a broad community of bamboo-specialist birds. The species was more readily found at other sites, including Oceanía, where it was encountered 19 times (1-4 times daily) during an 8-day survey. Fifteen of these encounters were aural and four were visual; two observations lasted $<1 \mathrm{~min}$, one lasted $\sim 20 \mathrm{~min}$, and one lasted $\sim 45 \mathrm{~min}$. At least three individuals were involved ( 2 were color-banded and 1 unbanded bird was later seen).

The first record for Bolivia involved at least four individuals at Extrema where the species was encountered on 11 occasions during a 4-day survey. Eight observations were aural and three were visual. Ten encounters were within $2 \mathrm{~km}$ of the Extrema guard-post and one encounter was within Peru near the Alto Peru guard-post. One bird was photographed and tape-recorded on 7 November 2004; at least three other individuals were heard or seen daily along a 2-km transect.

The first record for Brazil involved a single individual mist netted and photographed at
Parque Zoobotânico, Rio Branco on 22 May 1998 , although it was only identified to species in February 2006. The species was encountered repeatedly at Parque Zoobotânico from 1998 onwards: nine individuals were mist netted, one specimen was collected, and another window-killed individual was found and prepared as a specimen. Both specimens are currently housed at Museu Paraense Emílio Goeldi (MPEG), Belém, Brazil (Table 1).

The Rufous Twistwing was encountered at two further Brazilian sites. It was found once at Estação Ecológica do Rio Acre during $\sim 250$ hrs of field work: AA heard and taperecorded a single individual on 15 August 2005 in the dense understory of an extensive thicket of Guadua bamboo along a narrow creek (Igarapé do Tombo). Another individual was found by EG and Marcos Pérsio D. Santos on 20 November 2006 at Ramal Jarinal and a male was heard calling consistently throughout the morning from a Guadua bamboo thicket in terra firme forest. It was attracted with playback of its own calls and was collected; the skin is stored in MPEG (Table 1).

Three other localities have recently come to light (Fig. 1). The Rufous Twistwing was found three times near the Machiguenga community of Timpía $\left(12^{\circ} 04^{\prime} \mathrm{S}, 72^{\circ} 49^{\prime} \mathrm{W}\right.$; elevation $410 \mathrm{~m}$ ) on the Río Urubamba, Dpto. Cuzco, in 1998-2001 (N. G. Gerhart, pers. comm.). It was also recorded once nearby at Río Shihuaniro, a tributary of the Río Timpía, in October 1998 and once near Montetoni $\left(11^{\circ} 54^{\prime} \mathrm{S}, 72^{\circ} 21^{\prime} \mathrm{W}\right.$; elevation $550 \mathrm{~m}$ ) on the upper Río Camisea, Dpto. Cuzco in April 1998 (N. G. Gerhart, pers. comm.). A retrospective report involves a single individual in Guadua bamboo at Explorer's Inn, Tambopata $\left(13^{\circ} 08^{\prime} \mathrm{S}, 69^{\circ} 36^{\prime} \mathrm{W}\right.$; elevation $\left.250 \mathrm{~m}\right)$ in March 1984 (Michael Kessler, pers. comm.). The Río Shihuaniro locality is documented with a sound recording (ML 125894), as are the Timpía and Montetoni localities (N. G. Gerhart, pers. comm.); the Tambopata record is supported by a convincing description by an experienced observer. Adding the eight new localities to the original five produces a global range of $\sim 89,000 \mathrm{~km}^{2}$ (Fig. 1).

Mist Netting and Specimen Data.-Two birds were mist netted at Oceanía on 12 October 2004, a capture rate of one bird per $\sim 200$ net hrs (for 12-m nets). Both birds had 


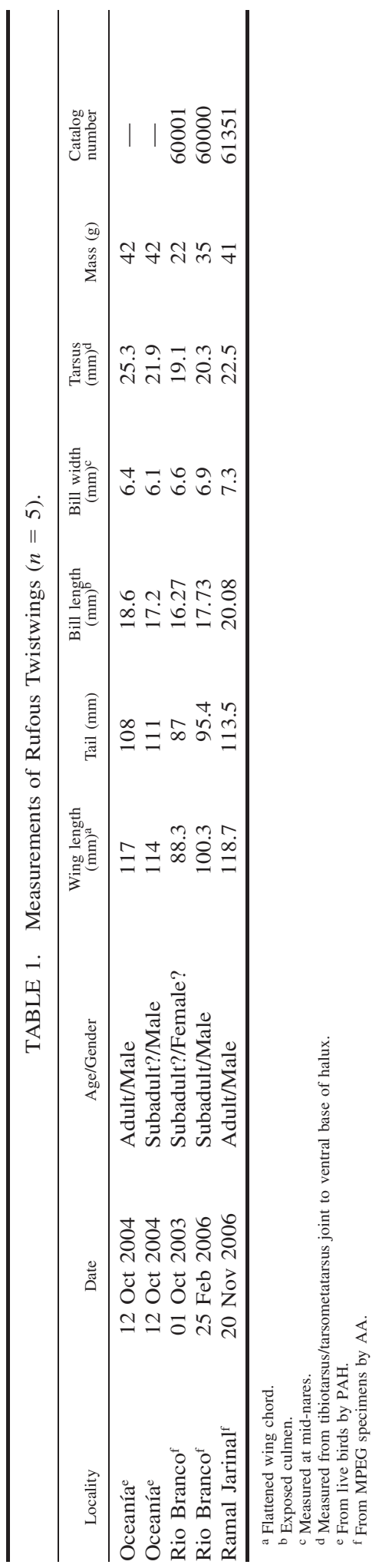

modified primaries suggesting they were males. One individual had $100 \%$ skull ossification and was molting secondaries, upper tail coverts, and extensively over the body; the other individual (possibly subadult) had roughly $50 \%$ skull ossification, shorter crest feathers, and no molt.

Two of nine birds mist netted at Rio Branco were banded with color bands (1998) and five with metal rings ( 2 in 1999, 1 in 2000, 1 in 2004, and 1 in 2005). Only one of these nine birds was recaptured (once) and only one bird was considered to be juvenile (in June) on the basis of downy underwing plumage and traces of a commisure. The trapping rate was $\sim$ one bird/1,800 net hrs (for $12-\mathrm{m}$ nets). Unfortunately, no biometric data were collected from these mist net captures. An immature bird found dead at Rio Branco in October was undergoing molt of remiges, rectrices, and contour feathers. The male collected at Ramal Jarinal on 20 November 2006 was an adult with enlarged testes.

Biometric data for two mist-netted birds and three specimens varied (Table 1). Measurements at Oceanía were from live birds and cannot be compared directly with other biometrics as specimens tend to shrink slightly during drying. Our sample is consistent with earlier data as males were considerably larger than females in mass and wing-length, but more similar in terms of bill and tarsus size. Total length of three fresh specimens was $18.4-24 \mathrm{~cm}$.

Habitat.-We report 44 encounters with the Rufous Twistwing (combining field observations with mist net data) of which 43 were in or immediately adjacent to patches of Guadua bamboo. It was recorded at Oceanía only within one large patch of Guadua bamboo. Eighteen of 19 encounters were in dense $\sim 5-\mathrm{m}$ tall bamboo and one was in taller, sparser bamboo under mature forest. It occurred at Extrema in large stands of Guadua bamboo, apparently preferring areas with a highly discontinuous tree canopy, occurring either in low treeless growth where the bamboo had collapsed (canopy height 2-4 m), or in taller bamboo supported by scattered trees (canopy height 10-25 m); two of 11 encounters were in the former habitat and seven in the latter habitat. The species was also heard and tape-recorded on two occasions at Extre- 
ma in an extensive patch of young secondary forest with a dense understory (canopy height $\sim 10-15 \mathrm{~m}$ ). This habitat contained only small amounts of bamboo but bordered an extensive stand of Guadua. The record at Montetoni was in scrubby secondary forest with a broken canopy, a dense understory of vines, and patches of Guadua bamboo; two records at Timpía were in similar broken secondary forest with dense bamboo dominating the understory (N. G. Gerhart, pers. comm.). We failed to detect the species at all sites in forest types lacking bamboo, although one recent observation by N. G. Gerhart (pers. comm.) was in dense secondary forest near Timpía with no bamboo component.

The Rufous Twistwing appears to be restricted to the understory. Birds at Oceanía foraged 1-3 $\mathrm{m}$ above ground, usually at the lower end of that scale. Similarly, individuals watched at Extrema did not ascend higher than $3 \mathrm{~m}$ above ground and spent most of their time at $1-2 \mathrm{~m}$.

Movement and Flight.-DJL and PAH observed one Rufous Twistwing continuously for $45 \mathrm{~min}$ at Oceanía as it performed 32 wing raises in the following sequence: RRRRRR LLLLLLR (R/L) LLRRRRRRRRRRLLLR LL (bracketed codes denote right and left wing simultaneous raises). The impression given during this bout, and throughout all other field observations, was a strong preference for single-wing raises, with both wings favored in roughly equal proportion. This individual made significantly more wing raises by raising the same wing repeatedly (23) than by switching between wings (7): $\chi^{2}=8.53, P=$ 0.003 (ignoring the simultaneous raise). Wing raising did not seem to correlate with any particular context, usually occurring randomly during bouts of vocalizing and foraging. There was no discernable increase in rate for birds accompanied by a second individual or in response to playback of calls.

The flight action of the Rufous Twistwing when moving between perches through the understory was erratic with slightly floppy and irregular downbeats. It was seen flying low across roads on three occasions at Extrema, at which time its flight was stronger and more direct.

Foraging Behavior.-The Rufous Twistwing foraged for prey from fairly open, often horizontal perches, slowly rotating the head to search at different angles. Individuals perched with an upright posture and flew to a new perch after 30-300 sec. They made abrupt sallies to small branches or leaves (bamboo and non-bamboo) to snatch invertebrates. One individual at Oceanía made three direct, upward, 1-m sallies from a horizontal bamboo stem to glean prey from bamboo leaves. It flew after each strike to a new perch at the same level as the original perch (once), or to a lower perch (twice). Another individual performed at least two upward sallies, two downward sallies, and one horizontal sally towards prey on small bamboo branches and leaves during a 45-min period. In one typical sally the bird traveled $\sim 30 \mathrm{~cm}$ upward, plucked a prey item from a dead bamboo branch (with dry leaves), and then dropped to a lower perch. It was observed in the same 45-min period beating one 20-mm orthopteran against a branch. Other prey items taken were small, unidentifiable, and swallowed immediately.

Vocalizations.-We grouped all vocalizations into three categories from a total of $\sim 150 \mathrm{~min}$ of recorded vocalizations. These categories may not encompass the species' entire repertoire, but it is likely they cover all regularly given vocalizations.

Vocalization \#1 is a loud, non-stereotyped, scolding series. It was heard during 25 encounters at Oceanía and Extrema. The full call is a loud series of 2-14 notes each containing at least three, usually four, harmonics (Fig. 2A) and is, at times, preceded by one or two loud pyew calls (Vocalization \#3). The phrase (without the pyew call) is fairly even in pitch and pace, and is usually repeated during prolonged bouts at a rate $(\overline{\mathrm{x}} \pm \mathrm{SD})$ of $13.8 \pm 8.9$ calls/min ( $n=30$ calls, from 3 bouts of calling by 2 individuals; Table 2).

Vocalization \#1 is deposited at the Macaulay Library, Cornell University (catalog numbers ML 124448, 124449, 124450). It was recorded at Oceanía and heard irregularly at Extrema. A similar call was also recorded at Extrema; it was more subdued with fewer notes per series (ML 124455, Fig. 3B). The loud version was heard throughout the day, often in late morning and mid-afternoon when most other species were silent; the quiet call was given at 1630 hrs on 6 November 2004. Both loud and quiet versions are similar in struc- 


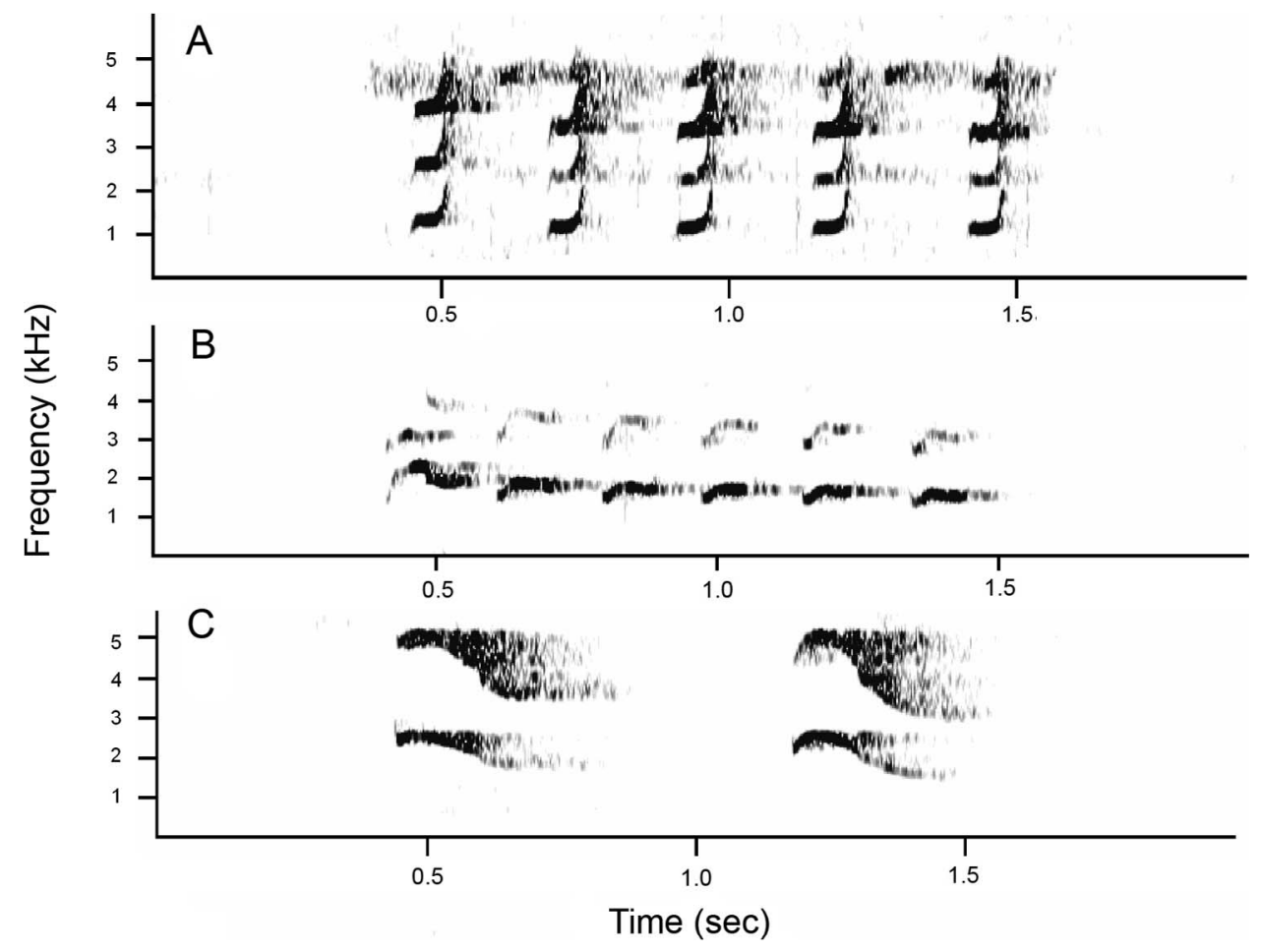

FIG. 2. Three call types of the Rufous Twistwing: (A) Vocalization \#1 (ML 124448), an agitation call, (B) Vocalization \#2 (ML 124453), apparently the song, and (C) Vocalization \#3 (ML 124454), the pyew call.

ture. Vocalization \#1 at times is given by agitated birds as a single note (ML 128954).

Vocalization \#2 was recorded once at Oceanía (ML 124452) and heard four times at Extrema (ML 124453). It consists of a loud chiming series of 5-7 evenly paced notes, descending in pitch, with the first note more disyllabic, ringing and prolonged than subsequent notes $(n=11$ calls, from 3 bouts of calling by 2 individuals; Table 2, Fig. 2B).

TABLE 2. Acoustic properties (mean $\pm \mathrm{SD}$ ) for known vocalizations of the Rufous Twistwing.

\begin{tabular}{lccc}
\hline & \multicolumn{3}{c}{ Vocalizations $^{\mathrm{d}}$} \\
\cline { 2 - 4 } \multicolumn{1}{c}{ Parameter } & $\# 1^{\mathrm{a}}$ & $\# 2^{\mathrm{b}}$ & $\# 3^{\mathrm{c}}$ \\
\hline Overall duration, sec & $0.97 \pm 0.57$ & $1.12 \pm 0.13$ & $0.33 \pm 0.05$ \\
Duration of first note, sec & $0.07 \pm 0.01$ & $0.15 \pm 0.02$ & \\
Duration of mid-note, sec & $0.07 \pm 0.01$ & $0.09 \pm 0.01$ & \\
Duration of final note, sec & $0.07 \pm 0.01$ & $0.11 \pm 0.01$ & 1.0 \\
Number of notes & $6.5 \pm 4.3$ & $6.4 \pm 0.8$ & \\
Note rate, notes/sec & $6.5 \pm 1.01$ & $5.9 \pm 0.11$ & $7.1 \pm 7.8$ \\
Call rate, calls/min & $13.8 \pm 8.9$ & $5.7 \pm 2.3$ & $5.19 \pm 0.13$ \\
Max frequency, $\mathrm{kHz}$ & $5.0 \pm 0.3$ & $2.20 \pm 0.19$ & $1.55 \pm 0.10$ \\
Min frequency, kHz & $1.01 \pm 0.10$ & $1.14 \pm 0.06$ & $3.64 \pm 0.16$ \\
Bandwidth, kHz & $4.0 \pm 0.29$ & $1.01 \pm 0.25$ & 13 \\
Number of calls measured & 30 & 11 & 13 \\
\hline
\end{tabular}

a Data from ML 124448 (locality: Oceanía, Peru; recordist: MJA), ML 124449 (locality: Oceanía, Peru; recordist: MJA), and ML 124455 (locality: Extrema, Bolivia; recordist: JAT).

b Data from ML 124452 (locality: Oceanía, Peru; recordist: PAH) and ML 124453 (locality: Extrema, Bolivia; recordist: JAT).

${ }^{c}$ Data from ML 124454 (locality: Extrema, Bolivia; recordist: NS).

d Harmonics were included in measurements for Vocalizations \# 1 and \# 3, but ignored for Vocalization \# 2 where they were much weaker. 


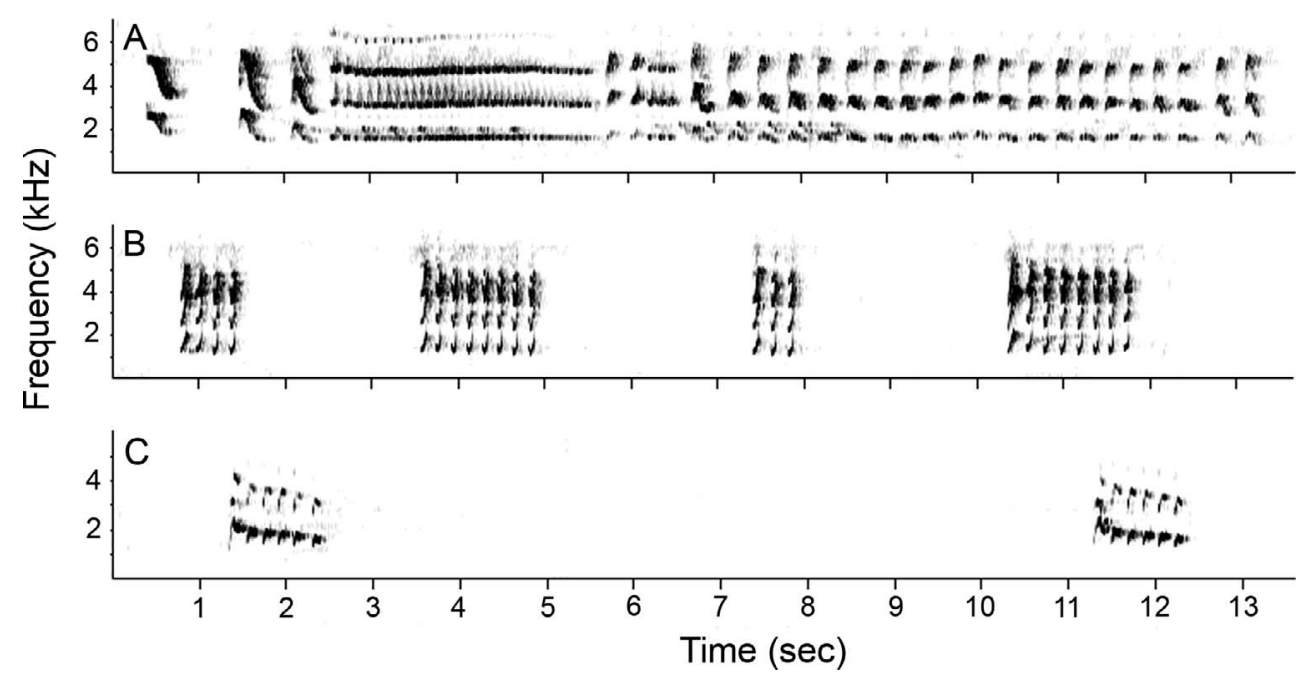

FIG. 3. Sonograms, showing delivery pattern over longer time-frames, of (A) Vocalization \#3, followed by a 'long call', (B) a subdued version of Vocalization \#1 (ML 124455), and (C) Vocalization \#2, all given by a single individual at Extrema, Dpto. Pando, Bolivia.

The individual notes have only two, rarely three, harmonics. The typical phrase is more stereotypic than Vocalization \#1 and, at a rate of $5.7 \pm 2.3$ calls $/ \mathrm{min}$, is distinctly slower (Fig. 3B, C). It is at times reminiscent in emphasis and pattern to the song of the Buffthroated Foliage-gleaner (Automolus ochrolaemus).

Vocalization \#3 was a loud whistle (pyew). It was heard during two encounters at Oceanía and Extrema. Analysis of a sample $(n=13$ calls, from three bouts by one individual at Extrema) indicates this call consists of a fundamental note with a single strong harmonic, given alone or in couplets (Table 2, Fig. 2C). Occasionally, Vocalization \#3 was given in a triplet followed by a series of trills lasting over $10 \mathrm{sec}$ (ML 124454, Fig. 3A). These trills are, at times, given without an introduction by Vocalization \#3 (e.g., ML 128955) and seem to be an accelerated version of Vocalization \#1.

The functional significance of these vocalizations is not known. Vocalization \#1 appears to be an agitation call, Vocalization \#2 is probably the song, and Vocalization \#3 can be described as a 'short call'. Vocalizations \#2 and \#3 have not previously been described and appear most likely to function in courtship. The most stereotyped call type is Vocalization \#2 (Fig. 2B), which was given at reg- ular intervals (Fig. 3C); it differs in structure and regularity from non-stereotyped agitation calls (Vocalization \#1: Figs. 2A, 3B).

The Rufous Twistwing vocalized frequently at Oceanía and Extrema with Vocalization \#1 heard throughout the day, especially between dawn ( $0530 \mathrm{hrs})$ and $\sim 0800 \mathrm{hrs}$. Calls were generally given in short bursts interspersed with long periods of silence but, at times, individuals called more or less consistently for periods up to $1 \mathrm{hr}$. At least two birds were heard counter-calling on one occasion at Oceanía between $\sim 1610$ and $1700 \mathrm{hrs}$. One individual at Extrema called intermittently in response to playback for several hours in the same area. All calls were given from low perches, 1-3 $\mathrm{m}$ above ground.

Playback of Vocalization \#1 at times (2/7 trials) resulted in noisy and aggressive behavior, including flights around the source of the playback, and loud vocalizing. More often, however, playback of Vocalization \#1 elicited no response or slight response (5/7 trials). Three playbacks of Vocalization \#2 elicited a stronger response than Vocalization \#1; all recipients approached slowly and vocalized loudly with the same call type. On one occasion, playback of Vocalization \#2 resulted in repeated production of Vocalization \#3.

Sociality and Mating System.-We observed two individual Rufous Twistwings to- 
gether on three occasions, twice at Oceanía and once at Extrema. At least two birds were calling simultaneously within $\sim 25 \mathrm{~m}$ of each other in the afternoon of 11 October 2004 at Oceanía and, the following day, two individuals were captured nearby in mist nets. The alarm calls of one bird drew the second into the net suggesting some cohesion between the two birds, both of which appeared to be males (with modified primaries).

Playbacks at Extrema resulted in two individuals giving Vocalization \#1 within $15 \mathrm{~m}$ of the observer and within $10 \mathrm{~m}$ of each other. The birds were not seen side-by-side and one individual (a male) contributed virtually all vocalizations. It was unclear whether these observations related to pairs, neighbors, or cooperative males near a calling post. It is possible two males were involved, or that repeated playback and response to playback attracted a female.

One (or two) Rufous Twistwings at Extrema were vocal in a small $\left(30 \mathrm{~m}^{2}\right)$ area of tall bamboo over a period of 4 days; at least one individual spent much of each day in the vicinity. Three or four vocal individuals at Oceanía appeared to call regularly from the central dense portion of the site with calling birds appearing to be relatively clumped in distribution.

\section{DISCUSSION}

Our results increase the known range of the Rufous Twistwing and confirm its presence in Bolivia and Brazil. The five sites from which the species was known prior to our study were distributed in two clusters in Peru (Lane et al. 2007) producing a total range of $3,400 \mathrm{~km}^{2}$. Adding the new localities presented here increases the known global range to $\sim 89,000$ $\mathrm{km}^{2}$ (Fig. 1). Our findings are consistent with the hypothesis that the species is a Guadua bamboo specialist distributed throughout southwest Amazonian bamboo forests, as predicted by Lane et al. (2007). Dense young secondary forest is also used by the species, usually in the vicinity of bamboo.

A sighting from Tambopata, Peru (Michael Kessler, pers. comm.) in 1984, 6 years before the type specimen was collected at Pakitza, becomes the first report of the species. The first record for Brazil is also reported retrospectively. EG took a series of in-hand pho- tographs of a puzzling bird mist netted at Rio Branco in 1998 and distributed them at the Brazilian Ornithology Congress (Rio de Janeiro) in the same year. Participants of the congress reached a consensus that it was a Brownish Twistwing and it was so listed in a paper about the avifauna of Parque Zoobotânico (Guilherme 2001). AA and EG re-examined the evidence in February 2006 including another specimen collected at the same site in 2003. They exchanged digital images with D. F. Lane, who confirmed that both records involved the Rufous Twistwing.

The two species of Cnipodectes presumably overlap in distribution with the Brownish Twistwing occurring north and south of the range of the Rufous Twistwing. To the north, the Brownish Twistwing occurs from Central America to lowland Amazonia south of the Amazon River (Meyer de Schauensee 1966, Lane et al. 2007); it is also known from the humid forests of Dpto. Pando, Bolivia (Montambault 2002, Moskovits et al. 2003) including Camino Mucden (Parker and Remsen 1987), $\sim 50 \mathrm{~km}$ from Extrema. This widespread form inhabits the tangled lower growth of terra firme forest throughout much of its range, the only exception being in Bolivia where it was repeatedly encountered in Guadua bamboo at Camino Mucden (Parker and Remsen 1987). Bamboo, some of it extensive, was surveyed in October 1999 at San Sebastián $\left(11^{\circ} 24^{\prime} \mathrm{S}, 69^{\circ} 01^{\prime} \mathrm{W}\right)$ on the Río Tahuamanu and Palmera $\left(11^{\circ} 30^{\prime} \mathrm{S}, 69^{\circ} 03^{\prime} \mathrm{W}\right)$ on the Río Muyumanu, Dpto. Pando, Bolivia (Alverson et al. 2000). Both sites are $\sim 30 \mathrm{~km}$ southeast of Extrema, but no species of $\mathrm{Cni}$ podectes was found. The apparent convergence in habitat requirements of Brownish Twistwing and Rufous Twistwing near the point of contact deserves further study.

The Rufous Twistwing is generally scarce and has been difficult to relocate at some sites (Lane et al. 2007). It has been reported only once at the intensively studied locality of Tambopata, and once during $>250$ hrs of field work at Estação Ecológica do Rio Acre. In addition, it is the only regional bamboo specialist that has not been recorded during 7 years of intensive fieldwork at CICRA. This absence is particularly of interest as the site contains extensive bamboo patches supporting all 19 of Kratter's (1997) bamboo specialist 
birds (obligate, near-obligate, and facultative), along with six other bird species strongly or seasonally associated with bamboo in this region. These results suggest the species is relatively specialized, or confined to larger or older blocks of habitat, as suggested by Lane et al. (2007).

Results from three sites indicate the Rufous Twistwing can be relatively common and easily encountered, especially when vocalizing. We recorded it 19 times in an 8-day survey at Oceanía and 11 times in a 4-day survey at Extrema suggesting that, at least in optimum habitat, encounter rates can be fairly high. Consistent captures at Rio Branco also indicate that some populations can be sedentary for periods of several years in suitable habitat. Overall, our data suggest that populations are patchy and unpredictable, and vary widely in density.

The Rufous Twistwing is known to sally from perches to catch insects and to lift one or other of its wings repeatedly (Lane et al. 2007). Our results affirm that wing raising is a common behavior in this species and suggest that wing raises tend to be given in onesided bouts. The function of wing raises in this species and several other genera of tyrantflycatcher remains unclear. They may serve as signals in intersexual contexts, although they are often given by solitary birds.

The function of modified primaries in both Cnipodectes species has not been fully explained, but primaries presumably are used in sound production (Zimmer 1939, Ridgely and Greenfield 2001, Lane et al. 2007). The wings of the male Brownish Twistwing make an audible mechanical pr'r'r'r'r' wing-rattle in flight (Hilty and Brown 1986) and a similar sound has been heard from the Rufous Twistwing (Lane et al. 2007). It is likely that sound production in both species is prominent during courtship display, as in other understory birds with modified wing feathers, i.e., $P i$ pra manakins and Smithornis broadbills, for example.

The Rufous Twistwing is more often heard than seen. The only vocalization previously reported is an agitation call which closely resembles an aggressive call of the Brownish Twistwing recorded in Ecuador (Krabbe and Nilsson 2003). Our vocal data enlarge the known repertoire of the Rufous Twistwing to at least three call types. In addition to the agitation call (Vocalization \#1) noted by Lane et al. (2007), we describe a 5-7 note song (Vocalization \#2), and a 1-3 note pyew call (Vocalization \#3). One Rufous Twistwing at Extrema, Bolivia responded strongly to playback of Vocalization \#2 and gave this call-type from a small area over 3 consecutive days, suggesting that it functions in advertising and courtship.

The song of the Brownish Twistwing contains 1-3 notes (Fig. 3C in Lane et al. 2007). It is perhaps analogous to the Rufous Twistwing's pyew call (Vocalization \#3), which is also given 1-3 times in succession (Fig. 2C, double version and Fig. 3A, triple version). A relationship between the pyew note of the $\mathrm{Ru}-$ fous Twistwing (Fig. 2C) and the song of the Brownish Twistwing (Fig. 2D in Lane et al. 2007) is suggested by similarities in their structure; both have a $2 \mathrm{kHz}$ fundamental with one major harmonic and a ridge-shaped introduction which leads into a level section. However, we believe it is unlikely the pyew note is the main song of the Rufous Twistwing as it is given rarely and from random points.

Vocalization \#2 is given at shorter intervals from fixed points and may be analogous to the stereotyped song of the Brownish Twistwing, although it is a longer, faster series of notes. The Rufous Twistwing does not appear to give an upwardly inflected cueet or kuuuu-wit note, the unsolicited single-note call of the Brownish Twistwing (Fig. 3D in Lane et al. 2007). It is possible the pyew call (Vocalization \#3) is homologous with the cueet call. This conclusion is supported by our observation that both calls are given at fairly long and irregular intervals.

The vocal repertoire of the Rufous Twistwing is similar to the Brownish Twistwing. However, presumed homologous vocalizations are diagnosably different between the two forms supporting their treatment as separate species. They may produce different mechanical noise; songs of the Brownish Twistwing are often introduced by bill snapping sounds (Hilty and Brown 1986), which have not yet been reported for the Rufous Twistwing. The wing-rattles of the two species have not been compared.

Male Brownish Twistwings sing from habitual song posts and do not appear to defend 
pair-territories (Parker and Remsen 1987). They therefore differ from males of most tyrant-flycatchers and resemble those of certain manakin genera (e.g., Neopelma and Tyranneutes) with polygamous breeding systems. Our observations suggest the behavior of male Rufous Twistwing is similar. The sexual size dimorphism in both Cnipodectes species is extreme for tyrant-flycatchers (Lane et al. 2007), again suggesting polygamy. Further research is required to clarify breeding biology and ranging behavior in Cnipodectes.

\section{CONSERVATION STATUS}

We estimate a global range of $\sim 89,000 \mathrm{~km}^{2}$ on the basis of all 13 known localities for the Rufous Twistwing (Fig. 1). However, our results fit the prediction of Lane et al. (2007) that the global range coincides with the discontinuous block of Guadua-dominated forest that extends over much of southeastern Peru, northern Bolivia, and western Amazonian Brazil. The total area of this habitat is unknown, but has been estimated at $\sim 121,000$ $\mathrm{km}^{2}$ (Nelson 1994) to $\sim 180,000 \mathrm{~km}^{2}$ (Saatchi et al. 2000).

The Rufous Twistwing is probably the least abundant and perhaps the most threatened of all bamboo specialists in Amazonia. The risk of extinction in the short term is low but recent development projects, including the paved Trans-Oceanica Highway, will increase human settlement and habitat destruction in the region (Nepstad et al. 2001, Conover 2003, Tobias and Brightsmith 2007). This may not be detrimental to the Rufous Twistwing because Guadua bamboo at times proliferates on deforested land and abandoned chacras (Griscom and Ashton 2003; D. F. Lane, pers. comm.), thereby increasing suitable habitat for the species. We note, however, that it is usually recorded in large, mature patches of Guadua bamboo and appears to be absent from stretches of more recent Guadua regrowth along the proposed route of the TransOceanica Highway. We also note the socioeconomic value of large bamboos and the increasing tendency to harvest them (Bystriakova et al. 2004). These factors suggest the extent of suitable habitat for the species may decline in the future.

The Rufous Twistwing is more or less restricted to patchy bamboo forests. It is gen- erally scarce, and we have shown it to be absent from some apparently suitable sites. More field data are needed before population size can be calculated but, for the purpose of classifying its conservation status according to current data and IUCN guidelines (IUCN 2001), we estimate this species may have a declining global population of $<10,000$ individuals, and that all subpopulations may contain fewer than 1,000 individuals. We therefore recommend that it be listed on the IUCN Red List as Vulnerable under criterion C2a (i) (IUCN 2001) with a caveat that data quality is poor and that further surveys may lead to future changes in status. Only a small part of the proposed distribution of the Rufous Twistwing has been surveyed and the threat from habitat disturbance remains unclear. Field surveys are required throughout the bamboo forests of southwest Amazonia and the extent of bamboo should be assessed at intervals, perhaps through remote sensing techniques.

\section{ACKNOWLEDGMENTS}

Permission for field work was granted in Peru by Instituto Nacional de Recursos Naturales (INRENA) and in Brazil by Instituto Brasileiro do Meio Ambiente e dos Recursos Naturais Renováveis (IBAMA). Logistical support and/or funding was provided by SOS Amazônia and WWF-Brazil (to Alexandre Aleixo), and Centro Nacional de Pesquisa para Conservação das Aves Silvestres (CEMAVE) (to Edson Guilherme). We are indebted to Macaulay Library for loan of sound recording equipment, and to N. C. A. Pitman and R. B. Huayllapuma for logistical support. We thank J. M. Barnett, S. H. M. Butchart, C. D. Cadena, N. G. Gerhart (deceased), Michael Kessler, D. F. Lane, P. C. Pulgarín R., Marcos Pérsio D. Santos, G. P. Servat, and Thomas Valqui for useful data, comments, and corrections. Fieldwork was funded in part by a Fulbright grant (to D. J. Lebbin), a CNPq/SECTAM joint Regional Development Research Program research grant \#35.0415/2004-8 (to Alexandre Aleixo), and a Junior Research Fellowship from Newnham College, University of Cambridge (to Nathalie Seddon).

\section{LITERATURE CITED}

Alverson, W. S., D. K. Moskovits, and J. M. ShopLAND (Editors). 2000. Bolivia: Pando, Río Tahuamanu. Rapid Biological Inventories Report 1. The Field Museum, Chicago, Illinois, USA.

Bystriakova, N., V. KaPOS, AND I. LySENKo. 2004. Bamboo biodiversity. UNEP-WCMC/INBAR, Cambridge, United Kingdom.

Conover, T. 2003. Peru's long haul: highway to riches or ruin. National Geographic June: 80-111. 
FitZPATRICK, J. W. 2004. Family Tyrannidae (tyrant flycatchers). Pages 170-462 in Handbook of the birds of the world (J. del Hoyo, A. Elliott, and D. A. Christie, Editors). Volume 9. Cotingas to pipits and wagtails. Lynx Edicions, Barcelona, Spain.

Griscom, B. W. AND P. M. S. Ashton. 2003. Bamboo control of forest succession: Guadua sarcocarpa in southeastern Peru. Forest Ecology and Management 175:445-454.

Guilherme, E. 2001. Comunidade de aves do campus e Parque Zoobotânico da Universidade Federal do Acre, Brasil. Tangara 1:57-73.

Hilty, S. L. AND W. L. BRown. 1986. A guide to the birds of Colombia. Princeton University Press, Princeton, New Jersey, USA.

IUCN. 2001. IUCN Red List categories and criteria. Version 3.1. IUCN Species Survival Commission, Gland, Switzerland and Cambridge, United Kingdom.

Krabbe, N. AND J. Nilsson. 2003. Birds of Ecuador, DVD-ROM. Bird Songs International, Westernieland, The Netherlands.

Kratter, A. W. 1997. Bamboo specialization by Amazonian birds. Biotropica 29:100-110.

Lane, D. F., G. P. Servat, T. Valqui H., and F. R. LAMBERT. 2007. A distinctive new species of tyrant flycatcher (Passeriformes: Tyrannidae: Cnipodectes) from southeastern Peru. Auk 124:762772.

Meyer de Schauensee, R. 1966. The species of birds of South America with their distribution. Academy of Natural Sciences, Philadelphia, Pennsylvania, USA.

Montambault, J. R. 2002. Informes de las evaluaciones biológicas de Pampas del Heath, Alto Madidi, Bolivia, y Pando, Bolivia. Conservation International, Washington, D.C., USA.

Moskovits, D. K., W. S. Alverson, AND I. Halm (Editors). 2003. Bolivia: Pando, Federico Roman, Rapid Biological Inventories 06. The Field Museum, Chicago, Illinois, USA.
NelsON, B. W. 1994. Natural forest disturbance and change in the Brazilian Amazon. Remote Sensing Reviews 10:105-125.

Nepstad, D., G. Carvalho, A. Barros, A. Alencar, J. CApobianca, J. Bishop, P. Moutinho, P. LefebVRE, S. U. Lopes, AND E. PRINS. 2001. Road paving, fire regime feedbacks, and the future of Amazon forests. Forest Ecology and Management 154:395-407.

PARKer, T. A. AND J. V. Remsen. 1987. Fifty-two Amazonian bird species new to Bolivia. Bulletin of the British Ornithologists' Club 107:94-107.

Ridgely, R. S. R. and P. J. Greenfield. 2001. The birds of Ecuador: a field guide. Volume 2. Princeton University Press, Princeton, New Jersey, USA.

Ridgely, R. S. R. AND G. TudoR. 1994. The birds of South America: the suboscine passerines. Volume 2. University of Texas Press, Austin, USA.

SaAtchi, S. S., B. Nelson, E. Podest, and J. Holt. 2000. Mapping land cover types in the Amazon Basin using $1 \mathrm{~km}$ JERS-1 mosaic. International Journal of Remote Sensing 21:1201-1234.

Schulenberg, T. S., C. A. Marantz, and P. H. EnGLISH. 2000. Voices of Amazonian birds: birds of the rainforest of southeastern Peru and northern Bolivia. Cornell Laboratory of Ornithology, Ithaca, New York, USA.

Silman, M. R., E. J. Ancaya, ANd J. Brinson. 2003. Los bosques de bambú en la Amazonía occidental. Pages 63-73 in Alto Purús: biodiversidad, conservación y manejo (R. Leite Pitman, N. Pitman, and P. Álvarez, Editors). Center for Tropical Conservation, Lima, Peru.

Tobias, J. A. And D. J. Brightsmith. 2007. Distribution, ecology and conservation status of the Blueheaded Macaw Primolius couloni. Biological Conservation 139:126-138.

ZimMER, J. T. 1939. Studies of Peruvian birds: notes on the genera Myiotriccus, Pyrrhomyias, Myiophobus, Onychorhynchus, Platyrinchus, Cnipodectes, Sayornis, and Nuttallornis. American Museum Novitates 1043:1-15. 